\title{
Intraoperative change of lactate level is associated with postoperative outcomes in pediatric cardiac surgery patients: retrospective observational study
}

\author{
Tomoyuki Kanazawa, Moritoki Egi ${ }^{*}$ Kazuyoshi Shimizu, Yuichiro Toda, Tatsuo Iwasaki and Hiroshi Morimatsu
}

\begin{abstract}
Background: A change of serum lactate concentrations appeared to be useful for predicting outcomes in various acute ill settings. However, there is little information on intraoperative change of lactate level in pediatric cardiac surgery patients.

Methods: We conducted a retrospective observational study of 459 children who received pediatric cardiac surgery to determine the association between change of lactate level after cardiopulmonary bypass (CPB) and patient prognosis (length of ICU stay and incidence of postoperative serious adverse events (SAEs)). We defined change of lactate level after CPB (LAC $\triangle$ ) as (final lactate level measurement in the operating room) - (lactate level measured at the end of (PBB). To study the independent association of LAC $\triangle$ with length of ICU stay, we used linear regression model.

Results: There were 1145 lactate measurements after CPB in this study cohort. After weaning from CPB, the serum lactate levels significantly increased from $2.1 \mathrm{mmol} / \mathrm{L}$ to $2.5 \mathrm{mmol} / \mathrm{L}(p<0.001)$. Patients with higher $L A C \Delta$ had significantly longer stay in ICU ( $p=0.017)$ and higher incidence of SAEs $(p=0.002)$. In multivariate linear regression analysis, higher LAC $\triangle$ showed a significant independent association with longer length of ICU stay.

Conclusions: Increased lactate level after CPB was associated with the longer duration of ICU stay and increased risk of postoperative SAEs in pediatric cardiac surgery patients. Future studies should be conducted to determine the clinical utility of intraoperative trend of lactate levels.
\end{abstract}

Keywords: Intraoperative, Lactate, Pediatric cardiac surgery, Cardiopulmonary bypass, Outcome

\section{Background}

Hyperlactatemia observed in postoperative intensive care unit were shown to have predictability for worse outcomes in pediatric patients undergoing cardiac surgery [1-6]. Early prediction of worse outcomes might be useful to improve outcome by widening the therapeutic time window or facilitating early intervention. In this regards, it could be desired to assess whether intraoperative lactate indices might have significant association with postoperative worse outcomes in pediatric patients undergoing cardiac surgery.

\footnotetext{
* Correspondence: moriori@tg8.so-net.ne.jp

Department of Anesthesiology and Resuscitology, Okayama University Hospital, 2-5-1 Shikatachou, Kitaku, Okayama, Okayama 700-8525, Japan
}

The increase of blood lactate level would be caused by increasing lactate production, decreasing lactate clearance at liver, kidney and other organs, or both simultaneously [7]. The change of lactate concentration appears to be useful for predicting outcomes in various acute ill settings [8-14]. Furthermore, one study has suggested that interventions aimed at targeting a lactate reduction in the critically ill with an abnormal lactate level may reduce organ failure and increase survival [15]. However, the change of lactate levels immediately following weaning from cardiopulmonary bypass (CPB) and its association with postoperative outcomes has been poorly investigated in pediatric patients undergoing cardiac surgery. 
Accordingly, to test the association between lactate change after CPB and patients' outcome, we conducted a retrospective observational study. We hypothesized that larger change of lactate level after CPB would be associated with increased the duration of ICU stay and the incidence of postoperative serious adverse events (SAEs) in pediatric patients who have undergone pediatric cardiac surgery.

\section{Methods \\ Design}

This is a retrospective observational study, for which the institutional review board of Okayama university waived the need for obtaining informed consent and approved its submission for publication.

\section{Study population and data sources}

This study was conducted in a tertiary teaching hospital that had 865 beds in the hospital and 8 beds in the pediatric cardiac ICU. We studied consecutive pediatric patients who underwent pediatric cardiac surgery during the period from January 1, 2007 to May 31, 2011. Inclusion criteria for the current study were age $<18$ years, undergone pediatric cardiac surgery that required $\mathrm{CPB}$, and with at least two lactate measurements after the end of CPB.

Data on age, gender, the lowest temperature during $\mathrm{CPB}$ and the duration of $\mathrm{CPB}$ were obtained from the patients' database, which had been prospectively collected by trained physicians. Coding for type of surgery was done by means of The Risk-Adjusted Classification for Congenital Heart Surgery Version 1 (RACHS-1) category [16]. We also obtained whether the patient received epinephrine administration after $\mathrm{CPB}$ or not.

\section{Lactate concentration measurements and lactate change after CPB}

All blood lactate concentrations were measured by an arterial blood gas analyzer (ABL 800, Radiometer Co., Copenhagen, Denmark). The lactate data for this study were corrected to a $\mathrm{pH}$ of 7.40. The lactate data reported here were stored and retrieved electronically. Blood samples were collected in standard pre-prepared heparinized blood gas syringes. The analyzer measured whole blood samples at 37 degrees. Trained physicians performed all blood gas analyses. Laboratory in the hospital complied with standards of the National Association of Testing Authorities. During the study period, arterial blood gas analyses were performed according to the decision of the anesthetic specialist. Lactate ringer's solution was not used for fluid therapy during perioperative management.

We calculated delta lactate after CPB (LAC $\Delta$ ) by the following: (last measurement of lactate level in the operating
$\left.\operatorname{room}\left(\operatorname{Lac}_{\text {Last }}\right)\right)$ - (lactate level measured at the end of $\left.\operatorname{CPB}\left(\operatorname{Lac}_{\text {First }}\right)\right)$.

\section{Primary and secondary outcomes}

Primary outcome was the duration of ICU stay. Secondary outcome was the incidence of at least one of SAEs. We defined SAEs including cardiac arrest, the requirement of extracorporeal membrane oxygenation (ECMO), and death during intensive care unit. All information was prospectively collected by trained physicians and stored electronically.

\section{Statistical analysis}

Data are presented as percentages (n) or as median $(25 \%$ quartile, $75 \%$ quartile). We first assessed the association between LAC $\Delta$ and the duration of ICU stay. Since its relationship may not be linear in nature, we separated patients into four subgroups according to each $1 \mathrm{mmol} / \mathrm{L}$ of LAC $\Delta$. This categorization was planned prior to analysis. We performed multivariate linear regression analysis with adjustment for the following covariates: age, gender, RACHS-1, the lowest temperature during $\mathrm{CPB}$, the duration of $\mathrm{CPB}$, the use of epinephrine after operation, the duration between Lac $_{\text {FIRST }}$ and $\mathrm{Lac}_{\text {Last }}$, Lac First and subgroups of LAC $\triangle$. The dependent variable was the duration of ICU stay.

To assess the influence of the duration between Lac FIRST and $\mathrm{Lac}_{\text {Last }}$, we further calculate the time weighted change of lactate level after CPB (LAC $\Delta \mathrm{tw})$; LAC $\Delta$ divided by the duration between Lac FIRST $_{\text {and }}$ Lac Last $_{\text {. We separated our }}$ patients into 4 groups according to quartile of LAC $\Delta$ tw (group1; $1^{\text {st }}$ quartile, group2; $2^{\text {nd }}$ quartile, group3; $3^{\text {rd }}$ quartile and $4^{\text {th }}$ quartile; group4), and performed same analysis with LAC $\triangle$.

$\mathrm{P}$ values of less than 0.05 were considered statistically significant. All statistical analyses were performed using commercially available statistical software (SPSS 19.0, SPSS Inc., Chicago, IL). Data was reported in accordance with the Strengthening the Reporting of Observational Studies in Epidemiology (STROBE) guidelines [17].

\section{Results}

Study flow

During study period, there were 459 pediatric patients who received pediatric cardiac surgery required $\mathrm{CPB}$ and had at least two lactate measurements after the end of $\mathrm{CPB}$. There was no patient with missing values.

\section{Patients' demographics and outcomes}

Among study cohort, the median age was 14 months and median RACHS-1 category was 3 . The median CPB time was 91 minutes. ICU stay in our cohort was a median of 6 days. There are 11 patients $(2.4 \%)$ who had at least one 
SAEs; 2 patients with cardiac arrests, 5 patients required ECMO postoperatively and 7 patients died in ICU.

\section{Lactate measurements after CPB}

There were 1145 lactate measurements after $\mathrm{CPB}$ in this study cohort. The median LAC $\Delta$ was $0.3 \mathrm{mmol} / \mathrm{L}$. After weaning from $\mathrm{CPB}$, the serum lactate levels were significantly increased from $2.1 \mathrm{mmol} / \mathrm{L}$ to $2.5 \mathrm{mmol} / \mathrm{L}(\mathrm{p}<0.001)$ (Table 1). The duration between $\mathrm{Lac}_{\mathrm{FIRST}}$ and $\mathrm{Lac}_{\mathrm{Last}}$ was median of 62 minutes.

\section{Univariate association of LAC $\Delta$ with outcomes}

Table 2 shows the duration of ICU stay among subgroups according to LAC $\triangle$. The population of each groups were 101 (LAC $\Delta \leqq 0 \mathrm{mmol} / \mathrm{L}), 235$ (LAC $\Delta 0-1 \mathrm{mmol} / \mathrm{L}), 86$ (LAC $\Delta 1-2 \mathrm{mmol} / \mathrm{L})$ and $37(\mathrm{LAC} \Delta>2 \mathrm{mmol} / \mathrm{L})$. The duration of ICU stay significantly differed among subgroups $(\mathrm{p}=0.017)$ and increased according to increase of LAC $\triangle$. To assess the influence of age on this association, we separated patients into two groups according to median of ages and performed same analysis in both groups. There was significant association between LAC $\Delta$ and length of ICU stay both in younger group (median of 3 months old, $\mathrm{p}<0.001$ ) and elder group (median of 3 years old , $\mathrm{p}=0.016$ ).

Figure 1 shows the incidence of SAEs among subgroups according to LAC $\triangle$. The incidence of SAEs significantly differed among subgroups $(\mathrm{p}=0.002)$ and increased when $\mathrm{LAC} \Delta$ was $>2 \mathrm{mmol} / \mathrm{L}$.

\section{Multivariate analysis}

In our multivariate linear regression model including possible confounders, LAC $\Delta>2 \mathrm{mmol} / \mathrm{L}$ was independently

\section{Table 1 Patient's demographics}

\begin{tabular}{|c|c|}
\hline Variables & median (IQR) or $n(\%)$ \\
\hline Age (months old) & $14(3,45)$ \\
\hline Gender (male) & $236 / 459(52.7 \%)$ \\
\hline RACHS-1 & $3(2,3)$ \\
\hline Lowest temperature during $\mathrm{CPB}\left({ }^{\circ} \mathrm{C}\right)$ & $32(28,32)$ \\
\hline CPB time, (min) & $91(66,128)$ \\
\hline The use of epinephrine after weaning from CPB & $60 / 459(13.1 \%)$ \\
\hline ICU stay (day) & $6(3,8)$ \\
\hline The duration between LaCFIRST and LaCLast $(\mathrm{min})$ & $62(37,87)$ \\
\hline $\operatorname{Lac}_{\text {First }}(\mathrm{mmol} / \mathrm{L})$ & $2.1(1.3,3.2)$ \\
\hline $\mathrm{LaC}_{\text {Last }}(\mathrm{mmol} / \mathrm{L})$ & $2.5(1.6,3.8)$ \\
\hline LAC $\Delta(\mathrm{mmol} / \mathrm{L})$ & $0.3(0,1.0)$ \\
\hline
\end{tabular}

RACHS-1: Risk-Adjusted classification for Congenital Heart Surgery Version 1. CPB: cardiopulmonary bypass.

ICU: intensive care unit.

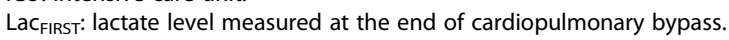

LaC ${ }_{\text {LAST: }}$ lactate level measured at the end of operation.

LAC $\triangle$ : change of lactate levels after weaning from cardiopulmonary bypass.
Table 2 The association of the duration of ICU stay with delta change of lactate levels according to each $1 \mathrm{mmol} / \mathrm{L}$ \begin{tabular}{llllll}
\hline Delta change of & $\leq 0$ & $0-1$ & $1-2$ & $2<$ & P-value
\end{tabular} lactate levels

ICU stay median (IQR) $\quad 5(3,7) \quad 5(3,8) \quad 6(3,11) \quad 6.5(4,13) \quad 0.017$

ICU; intensive care unit.

IQR; interquartile range.

associated with increased the duration of ICU stay $(\mathrm{p}=0.028)$ (Table 3). In this analysis, Lac FIRST $_{\text {fas }}$ not independently associated with the duration of ICU stay $(\mathrm{p}=0.41)$.

\section{The time weighted change of lactate level after CPB}

Length of ICU stay was significantly different among 4 groups according to the quartile of LAC $\Delta \mathrm{tw}(\mathrm{p}=0.049)$. The higher LAC $\Delta \mathrm{tw}$ was associated with increased length of ICU stay. We performed the another multivariate linear regression model using subgroups of LAC $\Delta \mathrm{tw}$ (Table 4). Group 4 (the larger LAC $\Delta \mathrm{tw}$ ) was independently associated with increased the duration of ICU stay $(\mathrm{p}=0.048)($ Table 4$)$.

\section{Discussion}

\section{Key finding}

We performed a retrospective study to evaluate the usefulness of intraoperative lactate change after $\mathrm{CPB}$ for predicting worse postoperative outcomes in pediatric cardiac surgery patients. In our study, the duration of ICU stay was significantly increased according to higher LAC $\Delta$. LAC $\Delta>2 \mathrm{mmol} / \mathrm{L}$ was also associated with the increased incidence of SAEs. Even after adjusting for relevant confounders, LAC $\Delta$ was independently associated with increased duration of ICU stay. This finding was consisted even when we used the time weighted change of lactate level after CPB.

\section{Comparison with prior studies}

While several studies have demonstrated that higher blood lactate levels at weaning from CPB [18], chest closure [18] and end of the operation [19,20], and maximum lactate level during the operation [21] were associated with worse outcomes in pediatric cardiac surgery patients, there has been a few report on the predictability of intraoperative change of lactate concentration for postoperative outcomes.

Munoz et al. have shown that increased lactate concentration during $\mathrm{CPB}$ (defined as the difference between baseline and the first lactate value obtained after $\mathrm{CPB}$ ) was associated with the risk of postoperative SAEs [1] in 174 pediatric cardiac surgery patients who required $\mathrm{CPB}$. In their multivariate logistic analysis, lactate change during $\mathrm{CPB}$ tended to be independently associated with mortality $(\mathrm{p}=0.13)$ and risk of complication $(\mathrm{p}=0.06)$. Park et al 


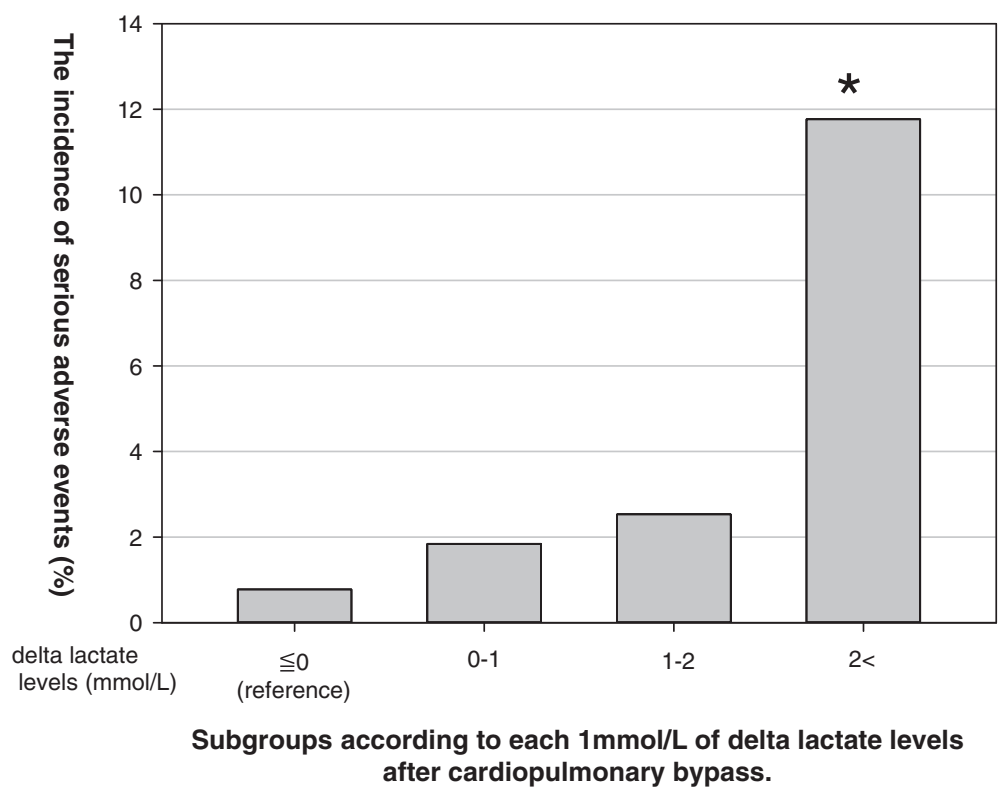

Figure 1 The incidence of serious adverse events among subgroups according to each $1 \mathrm{mmol} / \mathrm{L}$ of delta lactate levels after cardiopulmonary bypass. This figure shows the incidence of serious adverse events among subgroups according to delta lactate levels after cardiopulmonary bypass. The incidence of serious adverse events was significantly differed among subgroups $(p=0.002)$ and increased when delta lactate level was $>2 \mathrm{mmol} / \mathrm{L}$ in compared with those with $>0 \mathrm{mmol} / \mathrm{L}$.

have shown that the lactate change from $\mathrm{CPB}$ weaning to chest closure was significantly associated with major adverse events [18]. However, they did not assess its independent associations with patients' outcomes.

To our knowledge, this is the first study to assess the independent predictability of intraoperative lactate change after CPB for worse outcomes in pediatric cardiac surgery

Table 3 Multivariate analysis for duration of ICU stay

\begin{tabular}{|c|c|c|}
\hline & Coefficient & p-value \\
\hline Age (months old) & 0.007 & 0.54 \\
\hline Gender (male) & -0.4 & 0.85 \\
\hline RACHS-1 & 2.5 & 0.049 \\
\hline Lowest temperature during $\mathrm{CPB}\left({ }^{\circ} \mathrm{C}\right)$ & -0.6 & 0.08 \\
\hline CPB time (min) & 0.006 & 0.17 \\
\hline The use of epinephrine after weaning from CPB & 15.1 & $<0.001$ \\
\hline The duration between LaCFIRST and LaC Last $_{\text {(min) }}$ & -0.24 & 0.65 \\
\hline $\mathrm{LaC}_{\mathrm{FIRST}}(\mathrm{mmol} / \mathrm{L})$ & 0.7 & 0.42 \\
\hline $\mathrm{LAC} \triangle \leqq 0 \mathrm{mmol} / \mathrm{L}$ & reference & \\
\hline LAC $\Delta$ 0-1 mmol/L (vs. LAC $\Delta \leqq 0 \mathrm{mmol} / \mathrm{L})$ & 2.1 & 0.42 \\
\hline LAC $\Delta 1-2 \mathrm{mmol} / \mathrm{L}(\mathrm{vs} . \mathrm{LAC} \Delta \leqq 0 \mathrm{mmol} / \mathrm{L})$ & 0.8 & 0.81 \\
\hline $\mathrm{LAC} \Delta>2 \mathrm{mmol} / \mathrm{L}(\mathrm{vs} . \mathrm{LAC} \Delta \leqq 0 \mathrm{mmol} / \mathrm{L})$ & 10.3 & 0.028 \\
\hline
\end{tabular}

ICU: intensive care unit.

RACHS-1: Risk-Adjusted classification for Congenital Heart Surgery Version 1. CPB: cardiopulmonary bypass.

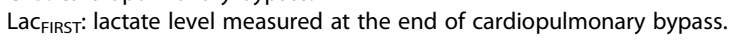

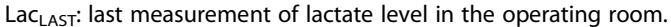

LAC $\triangle$ :change of lactate level after cardiopulmonary bypass. patients. Although results did not conflict with the prior study, further studies are required to confirm the clinical utility of this measure.

\section{Interpretation}

It might be relevant to find biomarkers which can identify patients who are at higher risk of worse outcomes.

Table 4 Multivariate analysis for duration of ICU stay with the subgroups according to the interquartile of time weighted delta lactate change

\begin{tabular}{|c|c|c|}
\hline & Coefficient & p-value \\
\hline Age (month) & 0.01 & 0.39 \\
\hline Gender (male) & 0.20 & 0.93 \\
\hline RACHS-1 & 1.75 & 0.19 \\
\hline Lowest temperature during $\mathrm{CPB}\left({ }^{\circ} \mathrm{C}\right)$ & -0.33 & 0.31 \\
\hline CPB time (min) & 0.015 & 0.55 \\
\hline The use of epinephrine after weaning from CPB & 16.8 & $<0.001$ \\
\hline LaCFIRST $(\mathrm{mmol} / \mathrm{L})$ & 1.17 & 0.17 \\
\hline Group1 (1 $1^{\text {st }}$ quartile of LAC $\left.\Delta \mathrm{tw}\right)$ & reference & \\
\hline Group2 ( $2^{\text {nd }}$ quartile of LAC $\Delta \mathrm{tw}$ ) (vs. Group1) & 2.60 & 0.39 \\
\hline Group3 (3 $3^{\text {rd }}$ quartile of LAC $\Delta$ tw) (vs. Group1) & 0.16 & 0.96 \\
\hline Group4 (4 ${ }^{\text {th }}$ quartile of LAC $\Delta$ tw) (vs. Group1) & 6.14 & 0.048 \\
\hline
\end{tabular}

ICU: intensive care unit.

RACHS-1: Risk-Adjusted classification for Congenital Heart Surgery Version 1. CPB: cardiopulmonary bypass.

LaC $_{\text {FIRST: }}$ lactate level measured at the end of cardiopulmonary bypass. LAC $\triangle$ tw: time weighted change of lactate level after cardiopulmonary bypass. 
Although our findings have a similarly with prior studies to show that the significant association of the increase of lactate concentration with increased risk of worse outcomes in other settings $[8-10,12,13]$, there were still few studies to assess the association between intraoperative lactate changes and outcomes in pediatric cardiac surgery patients.

In compared with the lactate concentration in postoperative ICU, intraoperative lactate change had advantage to promote the re-assess the quality of operation, cardiac function, circulatory blood volume and ventilator setting in operation room. This fact gives physicians the time windows to early intervention including administration of inotrope, adjustment of circulatory blood volume and alternation of ventilator settings. We should note that such an association existed even after adjusting the value of Lac $\mathrm{LIRST}_{\mathrm{FIR}}$ and the duration between Lac $\mathrm{FIRST}_{\text {and }}$ Lac $\mathrm{Last}_{\text {Lat }}$. This may suggest that irrespective of initial lactate value after $\mathrm{CPB}$ and duration between measurements, the lactate change after $\mathrm{CPB}$ was useful for prediction of worse outcomes.

\section{Limitation}

Our study has several limitations. First, it is retrospective in design and thus potentially subject to systematic error and bias. However, the clinical and electronic data were collected prospectively, are numerical in nature and were measured independently, and were thus not amenable to unintended manipulation.

Second, the study was conducted in only one hospital. The findings might be different for studies conducted in other hospitals or in other countries with different styles of management. However, it should be noted that there has been no multicenter study in which the association of lactate indices with outcomes in pediatric cardiac surgery patients was assessed. A multicenter study should be conducted in the future to refute or confirm our findings.

Third, there is no protocol for lactate measurements, and the duration of post CPB (between end of CPB and surgery) varied among patients. Such a time distribution of LAC $\triangle$ might affect our findings. However, we performed multivariate analysis adjusting the duration between Lac FIRST $_{\text {and }}$ Lac Last $_{\text {and }}$ and found higher LAC $\Delta$ had independent association with increased the length of ICU stay. Furthermore, we calculated the time weighted change of lactate level after $\mathrm{CPB}$ and also found that the higher LAC $\Delta \mathrm{tw}$ was independently associated with increased length of ICU stay.

Fourth, in current study, we used pre-planed subgroups according to each $1 \mathrm{mmol} / \mathrm{L}$ of LAC $\Delta$. Thus, our study could not determine the threshold of LAC $\Delta$ to maximize its predictability of worse outcomes. Accordingly, we performed post-hoc analysis to determine the threshold of LAC $\Delta$ to have larger area under the receiver operator characteristic curve (AUROC curve). Then, we found that $\mathrm{LAC} \geqq 1.6 \mathrm{mmol} / \mathrm{L}$ had largest AUROC curve for the length of ICU stay and the incidence of SAEs (Additional files 1 and 2). As this is post hoc analysis, future study is necessary to address the threshold of intraoperative change of lactate level for greater predictability of postoperative outcomes.

Fifth, we included patients with wide range of age. As age may influence the metabolic rate and oxygen tissue oxygen requirements after surgery, the association with LAC $\Delta$ and patients' outcomes may varied in different ages. We found that there was significant association between LAC $\Delta$ and length of ICU stay both in younger and elder patients. Nonetheless, we believed that future study is necessary to compare the magnitude of association between LAC $\Delta$ and outcomes among patients with different ages.

Sixth, we included the 26 children required circulatory arrest during surgery. This fact may influence our findings. However, even after excluded these 26 patients, we found that the duration of ICU stay significantly increased according to each category of LAC $\Delta(\mathrm{p}=0.017)$.

Finally, although we assessed the independent association of LAC $\triangle$ with outcomes with adjustment for age, gender, lowest temp CPB, CPB time, RACHS-1 the duration between Lac FIRST $_{\text {Ind }}$ and Lac $_{\text {Last }}$ and epinephrine use, there may be other confounders that influenced the association between LAC $\Delta$ and outcomes. In this regards, future study should be collected on these possible confounders to avoid potential biases.

\section{Conclusions}

In conclusion, increased lactate concentration after CPB was associated with risk of postoperative SAEs in pediatric cardiac surgery patients. Future studies should be conducted to confirm the potential utility of lactate change after $\mathrm{CPB}$ as a future therapeutic target or trigger.

\section{Additional files}

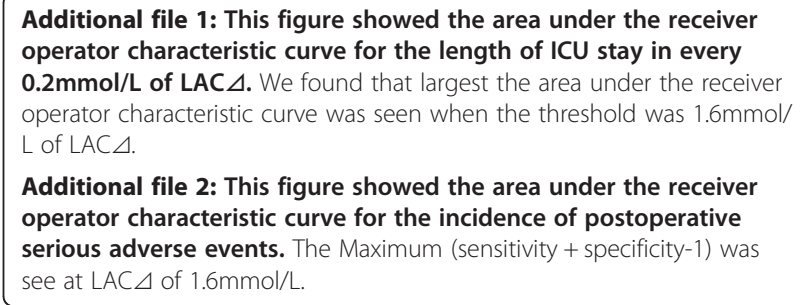

Additional file 2: This figure showed the area under the receiver operator characteristic curve for the incidence of postoperative serious adverse events. The Maximum (sensitivity + specificity-1) was see at LAC $\triangle$ of $1.6 \mathrm{mmol} / \mathrm{L}$.

\section{Abbreviations}

CPB: Cardiopulmonary bypass; SAEs: Serious adverse events; LAC $\triangle$ : Lactate level after cardiopulmonary bypass; RACHS-1: The Risk-Adjusted Classification for Congenital Heart Surgery Version 1; Lac Last $_{\text {: }}$ Last measurement of lactate level in the operating room; $\operatorname{LaC}_{\text {First }}$ : Lactate level measured at the end of cardiopulmonary bypass; ECMO: Extracorporeal membrane oxygenation; 
LAC $\Delta \mathrm{tw}$ : The time weighted change of lactate level after cardiopulmonary bypass; AUROC curve: Area under the receiver operator characteristic curve.

\section{Competing interests}

The authors declare that they have no competing interests.

\section{Authors' contributions}

TK: Conception and design, data collection, analysis and interpretation of data, drafting of the manuscript, critical revision of the manuscript for important intellectual content, approved the final version to be published. ME: Conception and design, analysis and interpretation of data, drafting of the manuscript, critical revision of the manuscript for important intellectual content, approved the final version to be published. KS: Data collection, interpretation of data, critical revision of the manuscript for important intellectual content, approved the final version to be published. YT: Data collection, interpretation of data, critical revision of the manuscript for important intellectual content, approved the final version to be published. Tl: Data collection, interpretation of data, critical revision of the manuscript for important intellectual content, approved the final version to be published. HM: Interpretation of data, critical revision of the manuscript for important intellectual content, approved the final version to be published.

\section{Acknowledgements}

This study was supported by the grants in aid for scientific research (No 26861233).

Received: 4 October 2014 Accepted: 20 February 2015

Published online: 08 March 2015

\section{References}

1. Munoz R, Laussen PC, Palacio G, Zienko L, Piercey G, Wessel DL. Changes in whole blood lactate levels during cardiopulmonary bypass for surgery for congenital cardiac disease: an early indicator of morbidity and mortality. J Thorac Cardiovasc Surg. 2000;119(1):155-62.

2. Cheifetz IM, Kern FH, Schulman SR, Greeley WJ, Ungerleider RM, Meliones JN. Serum lactates correlate with mortality after operations for complex congenital heart disease. Ann Thorac Surg. 1997;64(3):735-8.

3. Duke T, Butt W, South M, Karl TR. Early markers of major adverse events in children after cardiac operations. J Thorac Cardiovasc Surg. 1997;114(6):1042-52.

4. Charpie JR, Dekeon MK, Goldberg CS, Mosca RS, Bove EL, Kulik TJ. Serial blood lactate measurements predict early outcome after neonatal repair or palliation for complex congenital heart disease. J Thorac Cardiovasc Surg. 2000;120(1):73-80.

5. Cheung PY, Chui N, Joffe AR, Rebeyka IM, Robertson CM. Postoperative lactate concentrations predict the outcome of infants aged 6 weeks or less after intracardiac surgery: a cohort follow-up to 18 months. J Thorac Cardiovasc Surg. 2005;130(3):837-43.

6. Schumacher KR, Reichel RA, Vlasic JR, Yu S, Donohue J, Gajarski RJ, et al. Rate of increase in serum lactate level risk-stratifies infants after surgery for congenital heart disease. J Thorac Cardiovasc Surg. 2014;148(2):589-95.

7. Manikis P, Jankowski S, Zhang H, Kahn RJ, Vincent JL. Correlation of serial blood lactate levels to organ failure and mortality after trauma. Am J Emerg Med. 1995;13(6):619-22.

8. Wu WH, Niu YY, Zhang CR, Xiao LB, Ye HS, Pan DM, et al. Combined APACH II score and arterial blood lactate clearance rate to predict the prognosis of ARDS patients. Asian Pac J Trop Med. 2012;5(8):656-60.

9. Marty P, Roquilly A, Vallee F, Luzi A, Ferre F, Fourcade O, et al. Lactate clearance for death-prediction in severe sepsis or septic shock patients during the first 24 hours in Intensive Care Unit. An observational study. Ann Intensive Care. 2013;3(1):3.

10. Regnier MA, Raux M, Le Manach Y, Asencio Y, Gaillard J, Devilliers C, et al. Prognostic significance of blood lactate and lactate clearance in trauma patients. Anesthesiology. 2012;117(6):1276-88.

11. Murtuza B, Wall D, Reinhardt Z, Stickley J, Stumper O, Jones TJ, et al. The importance of blood lactate clearance as a predictor of early mortality following the modified Norwood procedure. Eur J Cardiothorac Surg. 2011;40(5):1207-14.

12. McNelis J, Marini CP, Jurkiewicz A, Szomstein S, Simms HH, Ritter G, et al. Prolonged lactate clearance is associated with increased mortality in the surgical intensive care unit. Am J Surg. 2001;182(5):481-5.
13. Meregalli A, Oliveira RP, Friedman G. Occult hypoperfusion is associated with increased mortality in hemodynamically stable, high-risk, surgical patients. Crit Care. 2004;8(2):R60-5.

14. Nichol A, Bailey M, Egi M, Pettila V, French C, Stachowski E, et al. Dynamic lactate indices as predictors of outcome in critically ill patients. Crit Care. 2011;15(5):R242.

15. Jansen TC, van Bommel J, Schoonderbeek FJ, Sleeswijk Visser SJ, van der Klooster JM, Lima AP, et al. Early lactate-guided therapy in intensive care unit patients: a multicenter, open-label, randomized controlled trial. Am J Respir Crit Care Med. 2010;182(6):752-61.

16. Jenkins KJ, Gauvreau K, Newburger JW, Spray TL, Moller JH, lezzoni LI. Consensus-based method for risk adjustment for surgery for congenital heart disease. J Thorac Cardiovasc Surg. 2002;123(1):110-8.

17. von Elm E, Altman DG, Egger M, Pocock SJ, Gotzsche PC, Vandenbroucke JP. The Strengthening the Reporting of Observational Studies in Epidemiology (STROBE) statement: guidelines for reporting observational studies. Lancet. 2007;370(9596):1453-7.

18. Park SJ, Kim HS, Byon HJ, Kim CS, Cheong IY, Kim JT. Intraoperative plasma lactate as an early indicator of major postoperative events in pediatric cardiac patients. Tohoku J Exp Med. 2012;228(3):239-45.

19. Alves RL, Aragao e Silva AL, Kraychete NC, Campos GO, Martins Mde J, Modolo NS. Intraoperative lactate levels and postoperative complications of pediatric cardiac surgery. Paediatr Anaesth. 2012;22(8):812-7.

20. Gupta P, Jines P, Gossett JM, Maurille M, Hanley FL, Reddy VM, et al. Predictors for use of temporary epicardial pacing wires after pediatric cardiac surgery. J Thorac Cardiovasc Surg. 2012;144(3):557-62.

21. Ranucci M, Isgro G, Carlucci C, De La Torre T, Enginoli S, Frigiola A. Central venous oxygen saturation and blood lactate levels during cardiopulmonary bypass are associated with outcome after pediatric cardiac surgery. Crit Care. 2010;14(4):R149.

\section{Submit your next manuscript to BioMed Central and take full advantage of:}

- Convenient online submission

- Thorough peer review

- No space constraints or color figure charges

- Immediate publication on acceptance

- Inclusion in PubMed, CAS, Scopus and Google Scholar

- Research which is freely available for redistribution 